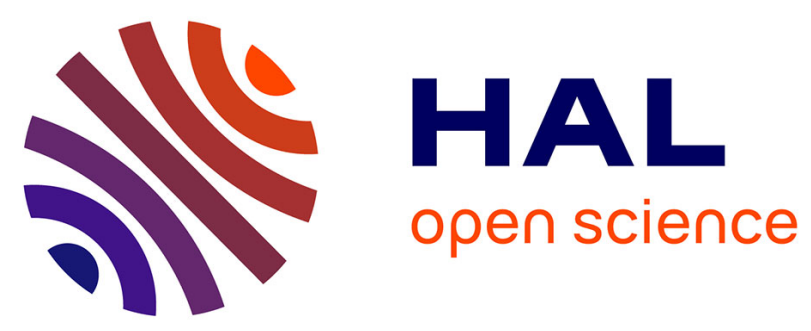

\title{
Counting and Phase Function Measurements with the LONSCAPE Instrument to Determine Physical Properties of Aerosols in Ice Giant Planet Atmospheres
}

Jean-Baptiste Renard, Olivier Mousis, Pascal Rannou, Anny Chantal Levasseur-Regourd, Gwenaël Berthet, Jean-Michel Geffrin, Edith Hadamcik, Nicolas Verdier, Aude-Lyse Millet, Daniel Daugeron

\section{To cite this version:}

Jean-Baptiste Renard, Olivier Mousis, Pascal Rannou, Anny Chantal Levasseur-Regourd, Gwenaël Berthet, et al.. Counting and Phase Function Measurements with the LONSCAPE Instrument to Determine Physical Properties of Aerosols in Ice Giant Planet Atmospheres. Space Science Reviews, 2020, 216 (2), pp.Article number 28. 10.1007/s11214-020-00653-2 . insu-02492388

\section{HAL Id: insu-02492388 \\ https://hal-insu.archives-ouvertes.fr/insu-02492388}

Submitted on 26 Feb 2020

HAL is a multi-disciplinary open access archive for the deposit and dissemination of scientific research documents, whether they are published or not. The documents may come from teaching and research institutions in France or abroad, or from public or private research centers.
L'archive ouverte pluridisciplinaire HAL, est destinée au dépôt et à la diffusion de documents scientifiques de niveau recherche, publiés ou non, émanant des établissements d'enseignement et de recherche français ou étrangers, des laboratoires publics ou privés. 


\title{
Counting and phase function measurements with the LONSCAPE instrument to determine physical properties of aerosols in ice giant planet atmospheres
}

\author{
Jean-Baptiste RENARD ${ }^{1}$, Olivier MOUSIS ${ }^{2}$, Pascal RANNOU ${ }^{3}$, Anny-Chantal \\ LEVASSEUR-REGOURD $^{4}$, Gwenaël BERTHET ${ }^{1}$, Jean-Michel GEFFRIN $^{5}$, Edith \\ HADAMCIK $^{6}$, Nicolas VERDIER ${ }^{7}$ \\ ${ }^{1}$ LPC2E-CNRS, 3A avenue de la recherche scientifique, F-45071 Orléans Cedex 2, France \\ 2 Aix Marseille Université, CNRS, LAM, F- 13388, Marseille France \\ ${ }^{3}$ GSMA, Université Reims Champagne-Ardenne, campus Sciences Exactes et Naturelles, F- \\ 51687 Reims, France \\ ${ }^{4}$ LATMOS, Sorbonne Université, CNRS, Campus Pierre et Marie Curie, F-75005 Paris, \\ France \\ ${ }^{5}$ Institut Fresnel, Faculté des sciences Saint Jérôme, F-13013 Marseille, France \\ ${ }^{6}$ LATMOS/IPSL, CNRS, Guyancourt, France \\ ${ }^{7}$ Centre National d'Etudes Spatiales, F-31401 Toulouse Eedex 9, France
}

Corresponding author: Jean-Baptiste RENARD, jean-baptiste.renard@cnrs-orleans.fr

Keywords: Aerosol, liquids, solids, ices, scattering, counting

\begin{abstract}
Measurements of light scattered by particles give insight into their physical properties (solid or liquid, size, shape, complex refractive index). We propose a novel instrument that provides in situ optical light-scattering measurements of aerosols in giant planet atmospheres, particularly in the ice giants Uranus and Neptune. Known as LONSCAPE (Light Optical Nephelometer Sizer and Counter for Aerosols for Planetary Environments), the instrument combines the particle counting technique of the LOAC balloon-borne aerosol counter with the well-known nephelometer technique to retrieve both the concentrations and phase functions of aerosols over 20 size classes in the $0.2-50 \mathrm{~mm}$ diameter size range. Such measurements allow us to distinguish between liquid, ice and solid (potentially carbonaceous) particles for all size classes, and thus to constrain the aerosols composition and their formation process. Given its low mass, size, and power requirements, LONSCAPE could become one of the key instruments selected to be part of the science payload of an atmospheric entry probe sent to the ice giants in the 2030s.
\end{abstract}

\section{Introduction: light scattering measurements in planetary atmospheres}

Light scattering observations by a cloud and/or by individual aerosols crossing a light source represent a powerful tool to retrieve some of the physical optical properties of liquid and/or solid particles in planetary atmospheres. In particular, solid particles in the Earth atmosphere are salts, minerals, carbonaceous materials, which may be in aggregates, and sometimes mixed with liquids. In ice giants, solid particles could be expected to be made of carbonaceous material, including diamonds, (Kraus et al., 2017). In the following, solid particles will refer to such carbonaceous compact or aggregated particles, which could be internally mixed with ices and liquids. The main properties that may be addressed are the size and the size distribution, the overall shape and the porosity, the complex refractive index, and thus the geometric albedo of the particles.

Two approaches may be used. The first one concerns the intensity (or brightness) of the light scattered at a given phase angle angle between the directions of illumination and observations) or scattering angle $\mathrm{q}$ (equal to $180^{\circ}$ - where the forward scattering corresponds 
thus the geometric albedo of the particles.

Two approaches may be used. The first one concerns the intensity (or brightness) of the light scattered at a given phase angle angle between the directions of illumination and observations) or scattering angle q (equal to $180^{\circ}$ - where the forward scattering corresponds to $180^{\circ}$ and the backscattering to $0^{\circ}$. It can be proportional to the particle size, although some oscillations in the phase curves for axially symmetrical particles could complicate the analysis. Such a relationship is used by aerosols counters to retrieve the concentrations and the size distribution of the Earth' atmospheric aerosols (Grimm et Eatough, 2009; Gao et al., 2016; Renard et al, 2016a). The lower limit of size detection of such instruments is of about 13 , where is the wavelength of measurements. For measurements made in the visible domain, the minimum detectable particle size is around $0.15 \mathrm{~m}$.

The second one concerns the change of the scattered intensity with the phase angle (so-called the phase function). The curve representing the phase function is expressed for in the $0^{\circ}-180^{\circ}$ range, and the instruments used for the measurement are often called nephelometers (e. g. Ragent et al., 1998, Gayet et al., 1997). The shape of the bulk phase curve, obtained for a cloud of particles, depends on the size of the aerosols but also on their shape and on their complex refractive index that can be a good indicator of the aerosols' nature.

In the case of liquid quasi-spherical particles, comparison of the measurements with theoretical calculations based on Mie scattering theory (van de Hulst, 1957) allows the retrieval of the size and the complex refractive index of polydisperse aerosols (e.g. Daugeron et al., 2007; Verhaege et al., 2009). Theoretical calculations have been extended to axially symmetrical particles (Mishchenko, 1991), to icy particles in clouds (Gayet et al., 1998), to cluster of spheres with T-matrix code (e.g. Mackowski and Mishchenko, 2011), and to aggregates of polydisperse monomers with Discrete Dipole Approximation technique (e.g., Draine and Flatau, 1994; Lasue et al., 2009).

In the case of irregularly shaped particles, experimental approaches are often used to compare the measured phase functions to reference phase functions obtained in the laboratory for levitating particles (Muňoz et al., 2012; Renard et al., 2014). Such data bases must contain tens or hundreds of phase functions for most of the particles significantly larger than a few $\mathrm{m}$ that can be present in atmospheres and in space. In particular, this approach has been used for a better understanding of the physical properties of Titan's aerosols and of dust in comet 67P/ Churyumov-Gerasimenko (Hadamcik et al., 2013; Levasseur-Regourd et al., 2019). Finally, the reference phase functions for non-spherical particles from a few $\mathrm{m}$ down to about $0.1 \mathrm{~m}$ can be obtained in the laboratory via the use of the microwave analog method (Vaillon and Geffrin, 2014), as presented at the end of section 3.2.

In the past, nephelometers and particle counters have operated in a variety of planetary atmospheres. On Venus, nephelometers were sent with Venera 9 and 10 (Marov et al., 1980), and with the main sounder and three smaller descent probes of Pioneer Venus (Ragent and Blamont, 1979, 1980). These instruments can make a fine description of the vertical structures of the aerosol and cloud layers that would not have been possible from orbit. Venera's nephelometers utilizing four phase angles $\left(0^{\circ}, 135^{\circ}, 165^{\circ}\right.$ and $\left.176^{\circ}\right)$ can determine the particle effective radius in addition to the vertical structure. Nephelometers on Pioneer-Venus only had one phase angle (at $15^{\circ}$ ) to probe the backscattered signal. This also enable the retrieval of the different cloud layers of Venus atmosphere. To complete observations of the PioneerVenus backscattering nephelometers, the Large probe Cloud Particle size Spectrometer (LCPS) on board the main sounder provided information of the particle granulometry (Knollenberg and Hunten, 1979, 1980). This instrument revealed the existence of two and maybe three particle modes.

A nephelometer was also onboard the Galileo Jupiter descent probe (Ragent et al., $1998)$ with measuring at five phase angles $\left(2^{\circ}, 110^{\circ}, 140^{\circ}, 164^{\circ}, 174.2^{\circ}\right)$. This probe descended into an atypical region of Jupiter; known as a hot spot. Although the atmosphere was unusually clear, the instrument nevertheless detected haze particles and several distinct layers of clouds that correlated to expected condensed species. With five angles they were able, as for Venera's nephelometers, to retrieve the extinction, optical constants and information on the particle size distribution (effective radius and variance) as well.

These instruments deployed into planetary atmospheres were only able to monitor the average radiance and could not serve as particle counters. In the three last decades, progress in hardware and material has allowed the development of nephelometers able to probe individual particles and, therefore, to measure particle granulometry. In this paper, we propose a novel space instrument that combines these two approaches, counting and nephelometry, for in situ measurements of the light scattered by individual aerosols in the atmospheres of Uranus or Neptune, to determine their physical properties. 
in naraware and material nas alıowed tne aeveıopment or nepneıometers abıe to probe individual particles and, therefore, to measure particle granulometry. In this paper, we propose a novel space instrument that combines these two approaches, counting and nephelometry, for in situ measurements of the light scattered by individual aerosols in the atmospheres of Uranus or Neptune, to determine their physical properties.

\section{Aerosols in ice giant atmospheres}

A recent review of the atmospheric composition and dynamical process of clouds and hazes in ice giant atmospheres is available in Mousis et al. (2018). This present knowledge comes from ground-based observations, from the Voyager2 flyby and from radiative-transfer modelling. To first order, the structure and properties accessible for clouds in both Uranus and Neptune's atmospheres are similar. They consist of a haze layer topping at 50-100 mbar, located above a thin methane cloud, and a base at about 1 bar. This cloud is itself above another cloud of $\mathrm{H}_{2} \mathrm{~S}$ ice located between 2 and 4 bar (Tice et al., 2013; de Kleer et al. 2015; Irwin et al. $(2016 \mathrm{a}, \mathrm{b})$. Also, due to the low temperatures, icy particles of methane and other hydrocarbons are present in the atmosphere of Uranus and Neptune (Sanchez-Lavega et al., 2004; Sanchez-Lavega, 2011). Figure 1 presents the vertical distribution of Neptune haze and clouds proposed by Mousis et al. (2018), based on the work of Baines and Hammel (1994), Baines et al. (1995), Irwin (2009), Irwin et al. (2017), with temperatures from Lindal (1992).

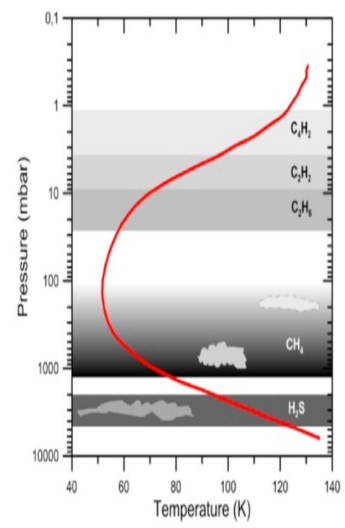

Fig.1 Vertical distribution of haze and cloud of Neptune (from Mousis et al., 2018)

The effective radius of the particles seems to be in the $0.1-0.2 \mu \mathrm{m}$ range for the stratospheric hazes, and in the $1-1.5 \mu \mathrm{m}$ range for the methane tropospheric cloud (Baines and Hammel, 1994; Irwin et al., 2017). More precisely for Uranus, the effective radius could increase from $0.05 \mathrm{~m}$ at 4 mbar to $0.3 \mathrm{~m}$ at 4 bar, with concentrations decreasing from $\sim 10$ to $\sim 2$ particles $\mathrm{cm}^{-3}$ with increasing pressures (Toledo et al., 2019).

However, since these results are derived from remote sensing measurements, they can suffer some significant uncertainties during the retrieval process. In situ measurements from instrumentation onboard an atmospheric probe would thus be mandatory to accurately determine the vertical structure of the hazes and clouds and their physical properties along the descent path of such a probe. The measurements of the scattering properties of the aerosols, their number density as a function of depth, their complex refractive indexes, and evidence for differences between liquid and icy particles would help to constrain the aerosols composition and the formation processes (Mousis et al., 2018; Hofstadter et al., 2019). Also, it would be possible to access clouds much deeper in altitude than those investigated via remote observations.

\section{The LONSCAPE concept}

\subsection{Light aerosols counter LOAC for Earth atmosphere}




\section{3. 'The LUNSCAPE' concept}

\subsection{Light aerosols counter LOAC for Earth atmosphere}

The best method to determine the size distribution and the concentration of aerosols is to use an aerosol counter that counts the particles one by one and classifies them in size classes. Among such instruments, the Light Optical Aerosols Counter (LOAC) has been used in the Earth's atmosphere since 2013 to retrieve the aerosol concentrations and size distributions for 19 size classes in the 0.2 - $50 \mathrm{~m}$ range (optical equivalent diameter). This instrument was developed to be operated on all kinds of atmospheric balloons, including weather balloons; it can be operated from the ground up to the middle stratosphere at an altitude of at least $35 \mathrm{~km}$ or 5 mbar (Renard et al., 2016a). The total weight of the gondola for terrestrial applications, including the optical chamber, the batteries, the pumping system, meteorological sensors and the telemetry, is of $1 \mathrm{~kg}$ for an electric consumption of about $3 \mathrm{~W}$.

As typical aerosol counters, the aerosols are injected into a laser beam (here at $=650$ $\mathrm{nm}$ ) inside an optical chamber through a pumping system, and the detectors (here photodiodes) record the scattered light. The novelty of LOAC (Renard et al., 2016b), presented in Figure 2, is to perform counting measurements at large phase angles, in the $160^{\circ}-170^{\circ}$ range, where the light scattered is dominated by diffraction and is globally not sensitive to the complex refractive index of the atmospheric aerosols. Simultaneous measurements are also conducted with LOAC at a phase angle in the $100^{\circ}-130^{\circ}$ range, where the light scattered is, on the opposite, very sensitive to the refractive index of the aerosols. These measurements at two very different angles of the phase function immediately provide key information concerning the nature of the aerosols (liquid, transparent solids, semitransparent solids, and absorbing solids) for the size classes where at least several particles were recorded during the integration time (which can be chosen between $10 \mathrm{~s}$ and $10 \mathrm{~min}$, depending on the aerosol concentrations). Also, no lens is mounted in front of the detectors, to prevent possible misalignment during changes in temperature and in pressure inside the optical chamber, especially during stratospheric balloon flights.

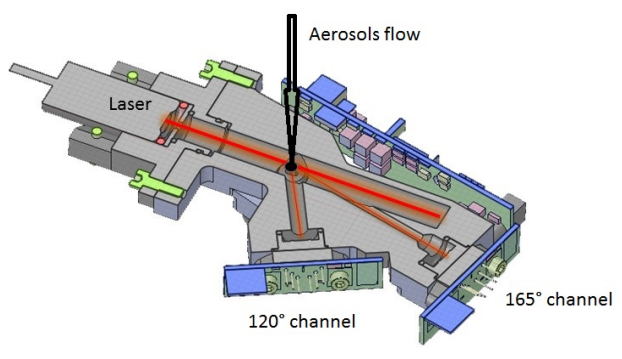

Fig.2 Current design of the LOAC instrument

About 200 weather balloons flights have been conducted since 2013, to monitor the Earth troposphere and stratosphere content; measurements were conducted during the balloon ascent at a vertical velocity in the $4-10 \mathrm{~m} \cdot \mathrm{s}^{-1}$ range, although some measurements can be conducted during descent under parachutes at a velocity up to few tens of $\mathrm{m} . \mathrm{s}^{-1}$. LOAC is also involved in the Strateole2 project, with 3-months flights in the equatorial lower stratosphere at a constant altitude (here $\sim 19 \mathrm{~km}$ ). The technical flight starting in November 2019 has shown that the instrument can work nominally for such a long period with an outside temperature of $-80^{\circ} \mathrm{C}$ and a pressure of $70 \mathrm{hPa}$.

In the free atmosphere, LOAC has allowed us to distinguish between liquid aerosols and solid particles (including ices) coming from Earth or from space. Also, measurements are conducted on the Earth's surface and under tethered balloons to monitor natural and anthropogenic aerosol concentrations. An example of concentration and size distribution measured inside a cloud on 15 May 2013 from the Puy de Dome Observatory (France) located at an altitude of $1465 \mathrm{~m}$, is presented in Figure 3; the combination of two angles measurements indicates that the aerosols are indeed liquid droplets. 
located at an altitude of $1465 \mathrm{~m}$, is presented in Figure 3; the combination of two angles measurements indicates that the aerosols are indeed liquid droplets.

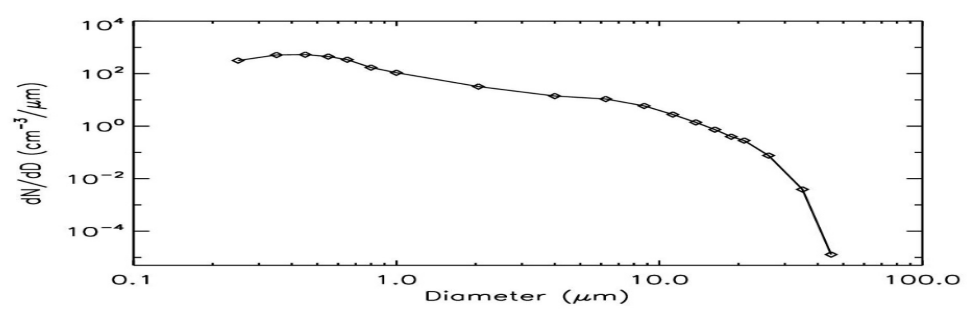

Fig.3 Example of size distribution and concentration inside a cloud on 15 May 2013 from Puy de Dome observatory (France); LOAC uncertainties are $\pm 20 \%$ for the higher concentrations and $\pm 60 \%$ for the lower concentrations

\subsection{New concept for planetary atmosphere measurements}

The current version of LOAC can provide the size distribution and the concentrations of aerosols and can estimate their main typology. Nevertheless, this estimate is not accurate enough to distinguish the various compositions of liquid droplets and icy particles that might exist in ice giant atmospheres. Adding more phase angles of measurements should enable a more accurate determination of the phase function for each size class.

Current nephelometers provide the bulk phase function for a cloud of particles but not for individual particles (Ragent et al., 1992; Barkey and Liou 2001). The mean radius or the size distribution and the bulk complex refractive index of the particles can be retrieved using a priori hypotheses on the shape of the size distribution, typically following a gaussian or a power law, and on the morphology of the particles (spherical, irregular). Then, degenerate solutions can occur while reproducing the atmospheric observations. Also, previous methods assume that the observed population of aerosols is homogeneous, with the same complex refractive index (and composition) for all size classes. In our new concept, the counting and the size distribution are obtained from the first angle measurement at around $165^{\circ}$ as already done with LOAC; the other angular measurements are used to retrieve the phase function for each size class. Thus, the refractive index can be directly retrieved for each size class by comparison of the measurements with modelling calculations for quasi symmetrical particles, or with phase functions available in data bases for irregular shaped particles. It is then possible to access to different populations of aerosols depending on their size. This instrumental concept is called LONSCAPE (Light Optical Nephelometer Sizer and Counter for Aerosols in Planetary Environments).

The more phase angles are measured, the more accurately the phase function will be determined. Laboratory, aircraft and rocket nephelometers usually use more than 20 angles, ideally spaced with a $5^{\circ}$ or $10^{\circ}$ step. In particular, such a small instrument performing measurements on dust samples injected into a chamber with 22 scattering angles has been operated successfully onboard CODAG ESA/MASER rocket flight in 1999 (LevasseurRegourd et al., 2001). To ensure the mechanical stability and the positioning of the detectors, the weight of the instrument must be of at least several $\mathrm{kg}$, and several tens of $\mathrm{cm}$ long and large, which is not compatible with a light space instrument for an atmospheric probe. Then a compromise must be found between the scientific objectives in terms of the accuracy of the phase function retrieval and the weight and size constraints.

An 11-angle instrument could be proposed, the first angle at around $170^{\circ}$ for the counting, and 10 following angles, typically with a $15^{\circ}$ step, for phase function measurements. Figure 4 presents such a possible optical chamber design having dimensions and weight acceptable for a deep space mission. Obviously, a dedicated electronic controller must be developed to record and analyze simultaneously the signal coming from the different photodiodes, and to control the light source. 
measurements. Figure 4 presents such a possible optical chamber design having dimensions and weight acceptable for a deep space mission. Obviously, a dedicated electronic controller must be developed to record and analyze simultaneously the signal coming from the different photodiodes, and to control the light source.

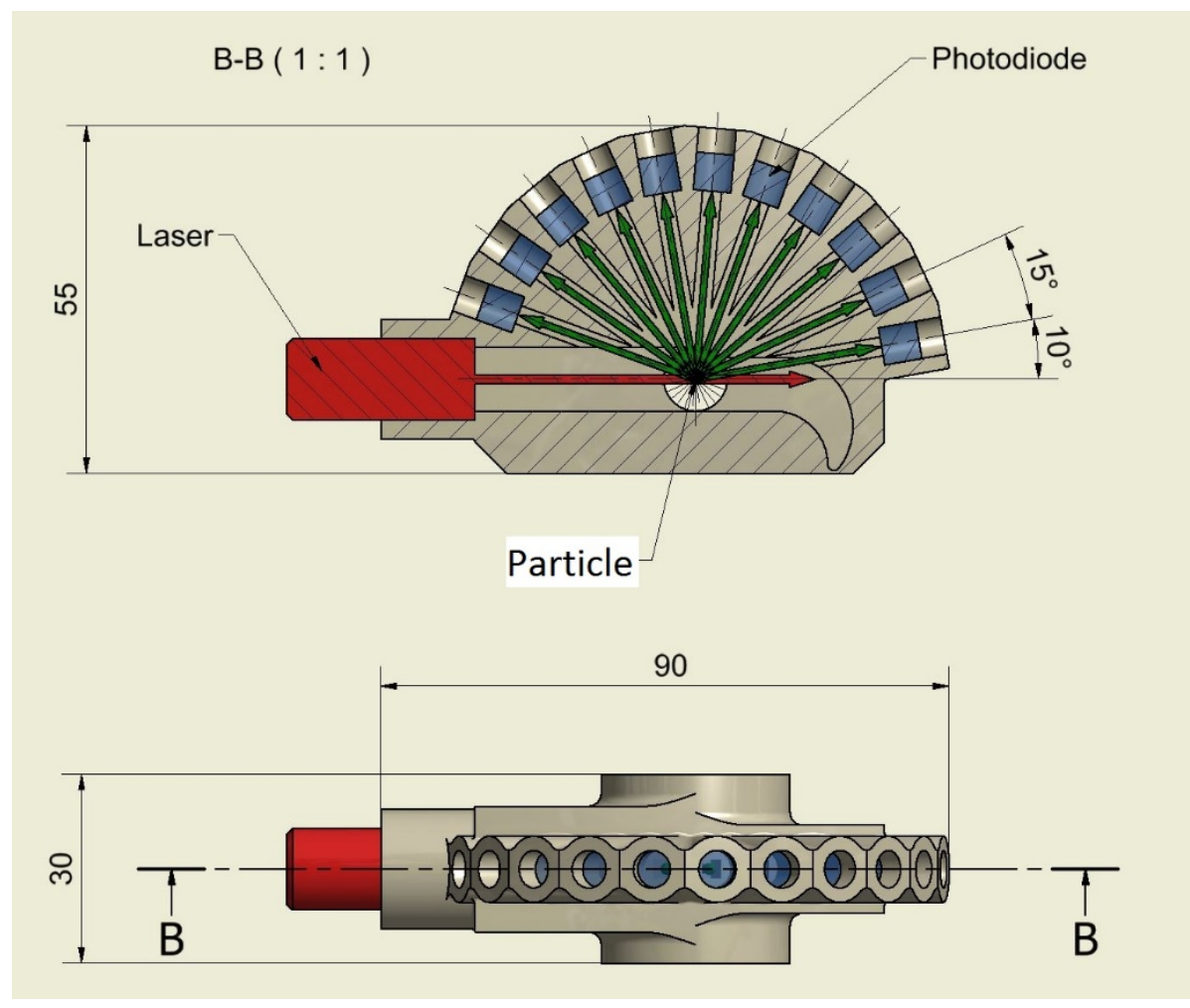

Fig.4 Possible design of the optical chamber for the LONSCAPE instrument (sizes are in mm)

With such a number of angles, it should be possible to retrieve the complex refractive index of the particles. Figure 5 presents an illustration of Mie scattering calculations for transparent and strongly absorbing droplets at $=650 \mathrm{~nm}$, for 3 sizes of monodisperse particles that are detectable with a conventional aerosol counter. The chosen refractive indexes are 1.45 and $1.45+0.5 \mathrm{i}$, respectively, typical of strongly absorbing aerosol like carbonaceous particles, but a large set of values must be considered when comparing the observations to theoretical calculations. The figure illustrates the difference in the phase curves depending on the size but also on the optical absorption properties of the particles (imaginary part of the complex refractive index). The values of the phase function for the 11 selected phase angles are plotted and establish that they can reproduce efficiently the overall shape of the curves.

Icy particles exhibit a large set of sizes and shapes (such as hexagonal, columns, plates, ...), thus producing phase curves with different behaviors (Baran, 2004). For some crystals, the curves may exhibit an increase in intensity for phase angles in the $155^{\circ}$ angle region (Liu et al., 1996). As for liquid particles the observations can be compared to theoretical calculations as Mie scattering, T-matrix approach, Discrete Dipole Approximation conducted for different shapes and complex refractive indexes.

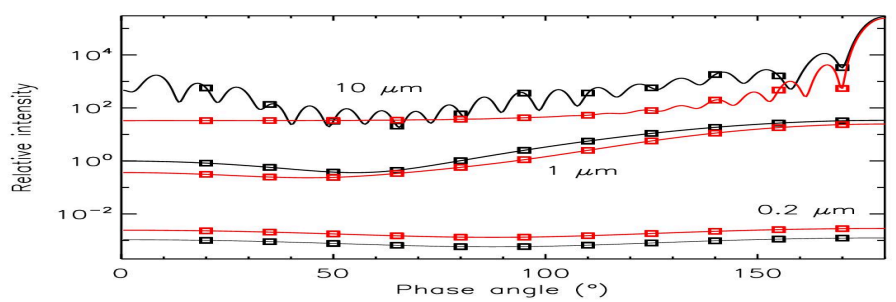


Fig.5 Mie scattering calculations for transparent (black lines) and strongly absorbing droplets (red lines) at $=650 \mathrm{~nm}$, for 3 sizes of monodisperse particles; the chosen complex refractive indexes are 1.45 and $1.5+0.5 i$, respectively, for illustration purpose. The squares represent the values of the phase function for the 11 angle positions proposed for LONSCAPE

The phase functions for solid irregular particles differ from those of liquid and icy particles. They can provide some indications on the shape and the nature of the particles, but also on the constituent grains (monomers) in the case of aggregates. As an example, figure 6 presents the bulk phase function for levitating aggregates of black carbon particles obtained in the laboratory with the imaging-goniopolarimeter PROGRA2 instrument (Francis et al., 2011; Levasseur-Regourd et al., 2019). The shape of the phase curve is very sensitive to the size of the monomers, the curve being deeper for aggregates with smaller monomers (the values for the 11 selected angle positions are also plotted). Such measurements can be coupled with modelling calculations (Figure 7) to better evaluate the effect of the complex refractive index, the fractal dimension and the number of monomers on the scattering properties of the aggregates.

Finally, a new database for the scattering properties in the visible domain of micronic and submicronic irregular particles having different shapes and refractive indices will be established in the laboratory using the microwave analogy method (Vaillon and Geffrin, 2014). The scattering properties are driven by the size parameter $X=2 \mathrm{pr} / \mathrm{l}$, where $r$ is the radius of the particle and I the wavelength of measurements; thus, by analogy, micronic particles in the visible domain have the same scattering properties than $\mathrm{cm}$-sized particles in the microwave domain. Such particles can be easily produced by 3-D printers, and their scattering properties will be obtained by the anechoic chamber instrumentation of the Fresnel Institute (Marseille, France). Such approach will allow us to better document the optical properties of compact and fractal particles having sizes typically in the $\mathrm{I} / 5-5 \mathrm{I}$ range $(0.1-3$ $\mathrm{mm}$ in the visible domain).

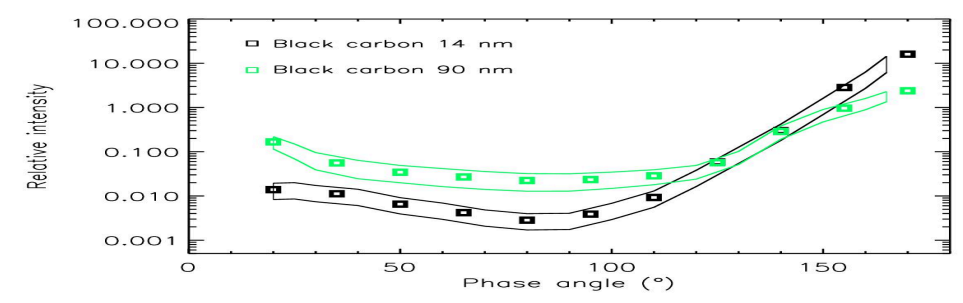

Fig.6 Laboratory measurements of the bulk scattering intensity for levitating aggregates of pure carbon particles with monomers of $14 \mathrm{~nm}$ (black lines, including uncertainty measurements) and of $90 \mathrm{~nm}$ (green lines) obtained with the PROGRA2 instrument; the squares represent the values of the phase function for the $\mathbf{1 1}$ angle positions proposed for LONSCAPE 

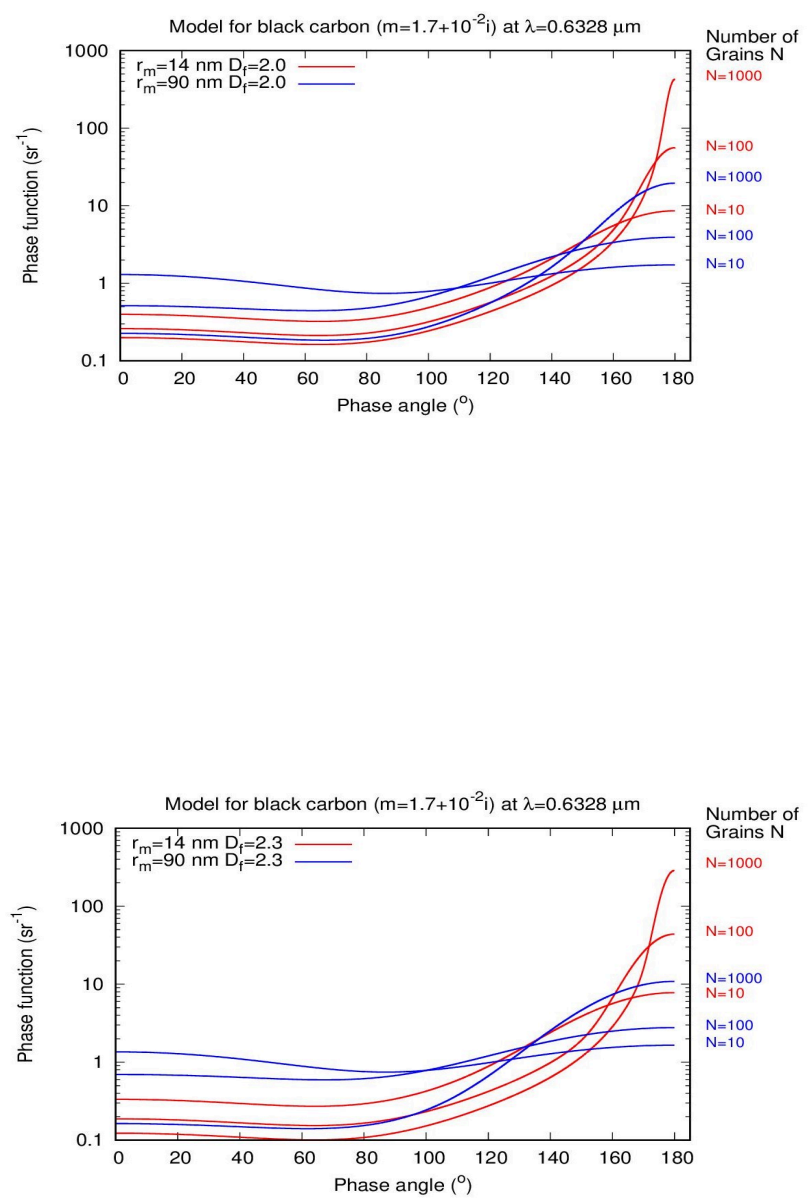

Fig.7 Theoretical calculations for fractal aggregates of black carbon monomers, as those in Fig. 5, with different morphologies. (top) Phase functions of fractal aggregates with a fractal dimension $\mathrm{Df}=\mathbf{2}$, two different grain sizes $(\mathbf{r m})$ and three number of grains $(\mathrm{N})$. (bottom) Same as for the 7-(a) except for $\mathrm{Df}=\mathbf{2 . 3}$

\section{Applications to ice giants and expected instrument performances}

In the LONSCAPE concept, it is possible to reduce the number of angles of measurement and to reconfigure their position, depending on the expected particles to be detected and the constraints of the space probe. Nevertheless, the retrieval of the complex refractive index will be less accurate when reducing the number of angles of measurements. Considering the modelling calculations and the experimental data already available in laboratory for the scattering functions (as those obtained with the PROGRA2 instrument and available at http://www.icare.univ-lille1.fr/progra2/indexeng.html), measurements at 4 angle, each with an aperture of few degrees, is the lower limit to be able to distinguish between liquid, icy and solid particles. The angle for counting must be around $170^{\circ}$. The other angles must be around $155^{\circ}$ for the detection of icy particles, $120^{\circ}$ where the difference between transparent and optically absorbent particles is often at its maximum, $70^{\circ}$ where liquid particles are at their minimum scattered intensity. A fifth angle at $20^{\circ}$ could be considered, since the phase functions of some particles increase with decreasing phase angle (e. g. Hadamcik et al., 2007).

Conventional photodiodes are sensitive enough to be used. The light source can be a laser working in the visible or near infrared domain, where the efficiency of the photodiodes is at its maximum (600-900 nm spectral region). Based on the present LOAC telemetry constraints for long-duration balloon flights, the data volume including counting from the 4 channels and some house-keeping parameters will be of about 150 kbytes per hour ( 40 bytes..$\left.^{-1}\right)$.

Following the experience gained from LOAC (Renard et al., 2016), about 20 size classes seems a good compromise to describe the aerosol size distribution. The smallest

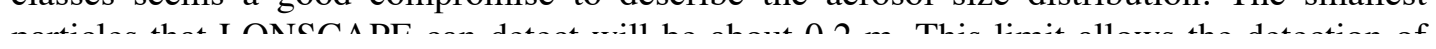


channels and some house-keeping parameters will be of about 150 kbytes per hour $(\sim 40$ bytes..$\left.^{-1}\right)$.

Following the experience gained from LOAC (Renard et al., 2016), about 20 size classes seems a good compromise to describe the aerosol size distribution. The smallest particles that LONSCAPE can detect will be about $0.2 \mathrm{~m}$. This limit allows the detection of haze particles close to the maximum of their size distribution (Toledo et al., 2019). Due to the dynamical range of the detectors, the upper limit of the size detection will be of about $50 \mathrm{~m}$. In the Earth atmosphere, numerous LOAC measurements inside cirrus have shown that ice particles have sizes mainly below $30 \mathrm{~mm}$. Thus, LONSCAPE could detect such large ice particles if they exit in ice giant atmospheres.

For a probe descending under parachutes in the atmosphere of Uranus or Neptune, the aerosols should be collected directly by an inlet parallel to descent motion, implying no need for a pumping system. To retrieve the aerosol concentrations, the relative velocity between the atmosphere and the probe must be accurately known. The descending vertical velocity is expected to be of several tens of $\mathrm{m} \cdot \mathrm{s}^{-1}$ (close to those encountered by LOAC during descent under parachutes in the middle stratosphere). Assuming a concentration of at least one particle $\mathrm{cm}^{-3}$ larger than $0.2 \mathrm{~mm}$ and based on the LOAC experience, an integration-time of 1 min or less could be sufficient to retrieve the size distribution and the phase function of the particle; this will provide a vertical resolution typically below $3 \mathrm{~km}$ (considering a velocity of $\left.50 \mathrm{~m} . \mathrm{s}^{-1}\right)$. The vertical resolution could be of the order of $1 \mathrm{~km}$ for lower vertical velocities and for higher aerosols concentrations.

The maximum concentrations that such an instrument could detect correspond to a few hundreds of particles $\mathrm{cm}^{-3}$, which seems well above the expected concentrations of the Uranus haze (Toledo et al. 2019). This limitation comes from the fact that the particles must cross the light beam one by one and is linked to the size of the volume sampled by the laser (about 1 $\mathrm{mm}^{3}$ ) and to the flux velocity. Following Poisson statistic, the concentration uncertainties, defined as the relative standard deviation, should be of $60 \%$ for aerosol concentrations of $10^{-2}$ $\mathrm{cm}^{-3}$, of $20 \%$ for $10^{-1} \mathrm{~cm}^{-3}$, and down to about $10 \%$ for concentrations higher than $1 \mathrm{~cm}^{-3}$.

The electronics must be able to record the light scattered by the aerosols when crossing the light beam at a velocity of several tens of $\mathrm{m} \cdot \mathrm{s}^{-1}$. Technical studies have shown that such performances can be achieved with current electronic components.

Considering the space constraints and the expected accuracy, preliminary studies show that the instrument could have a total mass of about $2 \mathrm{~kg}$ ( 5 times lighter than the Galileo Probe Nephelometer (Ragent et al., 1992), a size of $150 \times 100 \times 100 \mathrm{~mm}^{3}$, and an electric consumption of about $2 \mathrm{~W}$. Finally, the objectives are to perform the measurements down to the 10-bars level during the descent.

\section{Conclusions and perspectives}

We have presented a new concept for a light-scattering instrument, called LONSCAPE, which combines counting, sizing and nephelometric techniques. This concept is based the already existing LOAC instrument used at ground and in the Earth's atmosphere up to the middle stratosphere. LONSCAPE could provide the concentrations of liquid, icy and solid aerosols, typically in the $0.2-50 \mathrm{~m}$ size range; it could also discriminate between their different properties for various size ranges.

Technical studies on LONSCAPE are currently conducted with the support of the French Space Agency CNES. A laboratory prototype is expected to be available in 2020. A space prototype could then be realized in the following years, for technical tests with a CubeSat in Earth's orbit, probably with the two-angles geometry uses by LOAC as a first step to a space-version with several angles. The objective is to be able to propose an instrument well adapted to the study of haze and clouds particles in ice giant atmosphere for a future probe to be launched in the 2030s. The LONSCAPE concept could be also proposed for future explorations of the atmosphere of Venus (e. g. Titov et al., 2018) or Titan (e. g. Hörst and Tolbert 2013), onboard a probe or a balloon, for in situ determination of the concentration, the size distribution and the various natures of aerosols.

Acknowledgments: The LONSCAPE preliminary studies are funded by CNES in the frame of the "LOAC-S" project. The authors want to acknowledge the support by CNES, and thank the colleagues who have supported the idea to develop a space version of the Earth atmosphere aerosol counter LOAC, especially Jean-Pierre Lebreton (LPC2E) and François Poulet (IAS). 
of the "LOAC-S" project. The authors want to acknowledge the support by CNES, and thank the colleagues who have supported the idea to develop a space version of the Earth atmosphere aerosol counter LOAC, especially Jean-Pierre Lebreton (LPC2E) and François Poulet (IAS).

\section{References}

K. H. Baines, H. B. Hammel, Icarus 109, 20-39 (1994)

K. H. Baines, M. E. Mickelson, L E. Larson, D. W. Ferguson, Icarus 114, 328-340 (1995)

B. Barkey, K. N. Liou, Opt. Lett. 26(4), 232-234 (2001)

A. J. Baran, J. Quant. Spectrosc. Radiat. Transf. 89, 17-36 (1984)

D. Daugeron, J.-B. Renard, J.-B., P. Personne, G. Brun, J.-M. André, Measur. Sci. Technol. $18,632-638(2007)$

B. T. Draine, P. J. Flatau, J. Opt. Soc. Amer. 11, 1491-1499 (1994)

K. de Kleer, S. Luszcz-Cook, I. de Pater, M. Adamkovics, M., H. B. Hammel, Icarus 256, 120-137 (2015)

M. Francis, J.-B. Renard, E. Hadamcik, B. Couté, B. Gaubicher, M. Jeannot, J. Quant. Spectrosc. Radiat. Transf. 112, 1766-1775, (2011)

J.-F. Gayet, O. Crépel, J.-F. Fournol, S. Oshchepkov, Ann. Geophys. 15, 451-459 (1997)

J.-F. Gayet, F. Auriol, S. Oshchepkov, F. Schröder, C. Duroure, G. Febwe, J.-F. Foumol, O. Crépel, P. Personne, D. Daugeon, Geophys. Res. Lett. 25(7,) 971-974 (1998)

H. Grimm, D. J. Eatough, J. Air Waste Manage. Assoc. 59, 101-107 (2009)

R. S. Gao, H. Telg, R. J. McLaughlin, S. J. Ciciora, L. A. Watts, M. S. Richardson, J. P. Schwarz, A E. Perring, T. D. Thornberry, A. W. Rollins, M. Z. Markovic, T. S. Bates, J. E. Johnson, D. W. Fahey, Aeros. Sci. Technol., 50(1), 88-99 (2016)

E. Hadamcik, J.-B. Renard, J. Lasue, A.C. Levasseur-Regourd, J. Blum, R. Schraepler, J. Quant. Spectrosc. Radiat. Transf. 106, 74-89, (2007)

E. Hadamcik, J.-B. Renard, G. Alcouffe, G. Cernogora, A. C. Levasseur-Regourd, C. Szopa, Planet. Space Sci. 57, 1631-1641 (2013)

M. Hofstadter, A. Simon, S; Atreya, D. Banfield, J. J. Fortney, A. Hayes, M. Hedman, G. Hospodarsky, K. Mandt, A. Masters , M. Showalter, K. M. Soderlund, D. Turrini, E. Turtle, K. Reh, J. Elliott, N. Arora, A. Petropoulos, Planet. Space Sci. 77, 104680 (2019)

S. M. Hörst, M. A. Tolbert, Astrophys. J. Lett, 770, L10 (2013)

P. G. J. Irwin, Giant Planets of Our Solar System, Springer Praxis Books, Springer Berlin Heidelberg (2009)

P. G. J. Irwin, L. N. Fletcher, P. L. Read, D. Tice, D., I. de Pater, G. S. Orton, N. A. Teanby, G. R. Davis, Icarus 264, 72-89, (2016a)

P. G. J. Irwin, L. N. Fletcher, D. Tice, S. J. Owen, G. S. Orton, N. A. Teanby, G. R. Davis, Icarus 271, 418-437 (2016b)

P. G. J. Irwin, M. H. Wong, A. A. Simon, G. S. Orton, D. Toledo, Icarus 288, 99-119, (2017)

R. G. Knollenberg, D. M. Hunten, Science 203 (4382), $792-795$ (1979)

R. G. Knollenherg. D. M. Hunten. I. Geonhvs. Res.: Snace Phvsics 85(A13). 8039.8058 
P. G. J. Irwin, M. H. Wong, A. A. Simon, G. S. Orton, D. Toledo, Icarus 288, 99-119, (2017)

R. G. Knollenberg, D. M. Hunten, Science 203 (4382), $792-795$ (1979)

R. G. Knollenberg, D. M. Hunten, J. Geophys. Res.: Space Physics 85(A13), 8039,8058 (1980.)

D. Kraus, J. Vorberger, A. Pak, N. J. Hartley, L. B. Fletcher, S. Frydrych, E. Galtier, E. J. Gamboa, D. O. Gericke, S. H. Glenzer, E. Granados, M. J. MacDonald, A. J. MacKinnon, E. E. McBride, I. Nam, P. Neumayer, M. Roth, A. M. Saunders, A. K.

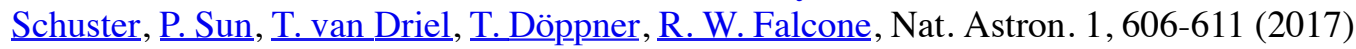

J. Lasue, A. C. Levasseur-Regourd, E. Hadamcik, G. Alcouffe, Icarus 199, 129-144, (2009)

A. C. Levasseur-Regourd, V. Haudebourg, M. Cabane, J.-C. Worms, ESA SP 454, 797-802 (2001)

A. C. Levasseur-Regourd, J.-B. Renard, E. Hadamcik, J. Lasue, I. Bertini, I., M. Fulle, Astron. Astrophys., 630, A120 (2019)

G. F. Lindal, Astron. J. 103, 967-982 (1992)

C. Liu, P. R. Jinas, C. P. R. Saunders Ann Geophys. 14, 1192-1197 (1996)

D. W. Mackowski, M. I., Mishchenko, J. Quant. Spectrosc. Radiat. Transf. 112, 2182-2192 (2011)

M. Y. Marov, V. E. Lystsev, V. N. Lebedev, N. L. Lukashevich, V. P. Sharp, Icarus 44, 608$639(1980)$

M. I. Mishchenko, J. Opt. Soc. Amer. 8(6), 871-882 (1991)

O. Mousis, D. H. Atkinson, T. Cavalié, L. N. Fletcher, M. J. Amato, S. Aslam, F. Ferri, J.-B.

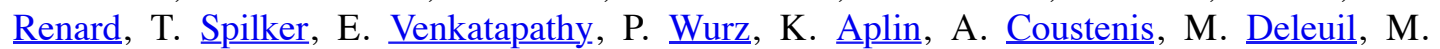
Dobrijevic, T. Fouchet, T. Guillot, P. Hartogh, T. Hewagama, M. D. Hofstadter, V. Hue, R. Hueso, J.-P. Lebreton, E. Lellouch, J. Moses, S. Orton, J. C. Pearl, A. Sanchez-Lavega, A., Simon, O. Venot, J. H. Waite, R. K. Achterberg, S. Atreya, F. Billebaud, M. Blanc, F. Borget, B. Brugger, S. Charnoz, T. Chiavassa, V. Cottini, V., L. d'Hendecourt, G. Danger, T. Encrenaz, N. J. P. Gorius, L. Jorda, B. Marty, R. Moreno, A. Morse, C. Nixon, K. Reh, T.

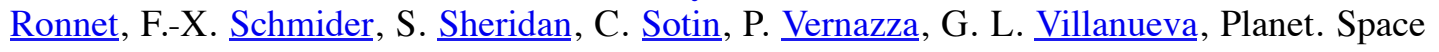
Sci. 155, 12-40 (2018)

O. Muňoz F. Moreno D. Guirado D. D. Dabrowska H. Volten, J. W. Hovenier J. Quant. Spectrosc. Radiat. Transf. 113 (7), 564-574 (2012)

B. Ragent, J. Blamont, Science. 203(4382), 790-792 (1979)

B. Ragent, J. Blamont, J. Geophys. Res. 85, 8089-8105 (1980)

B. Ragent, C. A. Privette, P. Avrin, J. G. Waring, C. E. Carlston, T. C. D. Knight, J. P. Martin, Space Sci. Rev. 60, 179-201 (1992)

B. Ragent, D. S. Colburn, J. A. Rages, T. C. D. Knight, P. Avrin, G. S. Orton, P. A. Yanamandra-Fisher, G. W. Grams, J. Geophys. Res. 103(EI0), 22,891-22,909 (1998)

J.-B. Renard, E. Hadamcik, B. Couté, M. Jeannot, A. C. Levasseur-Regourd, J. Quant. Spectrosc. Radiat. Transf. 146, 424-430 (2014)

J.-B. Renard, F. Dulac, G. Berthet, T. Lurton, D. Vignelles, F. Jégou, T. Tonnelier, M. Jeannot, B. Couté, R. Akiki, N. Verdier, M. Mallet, F. Gensdarmes, P. Charpentier, S. Mesmin, V. Duverger, J.-C. Dupont, T. Elias, V. Crenn, J. Sciare, P. Zieger, M. Salter, T. Roberts, J. Giacomoni, M. Gobbi, E. Hamonou, H. Olafsson, P. Dagsson-Waldhauserova, C. CamyPeyret, C. Mazel, T. Décamps, M. Piringer, J. Surcin, J., D. Daugeron, Atmos. Meas. Tech. 9, 3673-3686 (2016) 
Duverger, J.-C. Dupont, T. Elias, V. Crenn, J. Sciare, P. Zieger, M. Salter, T. Roberts, J. Giacomoni, M. Gobbi, E. Hamonou, H. Olafsson, P. Dagsson-Waldhauserova, C. CamyPeyret, C. Mazel, T. Décamps, M. Piringer, J. Surcin, J., D. Daugeron, Atmos. Meas. Tech. 9, 3673-3686 (2016)

J.-B. Renard, F. Dulac, G. Berthet, T. Lurton, D. Vignelles, F. Jégou, T. Tonnelier, M. Jeannot, B. Couté, R. Akiki, N. Verdier, M. Mallet, F. Gensdarmes, P. Charpentier, S. Mesmin, V. Duverger, J.-C. Dupont, T. Elias, V. Crenn, J. Sciare, P. Zieger, M. Salter, T. Roberts, J. Giacomoni, M. Gobbi, E. Hamonou, H. Olafsson, P. Dagsson-Waldhauserova, C. Camy-Peyret, C. Mazel, T. Décamps, M. Piringer, J. Surcin, J., D. Daugeron, Atmos. Meas. Tech., 9, 1721-1742 (2016)

A. Sanchez-Lavega, A., An Introduction to Planetary Atmospheres (CRC press, Taylor\& Francis group, Boca Raton, 2011)

A. Sanchez-Lavega, S. Pérez-Hoyos, S., R. Hueso, Am. J. Phys. 72, 767-774 (2004)

D. S. Tice, P. G. J. Irwin, L. N. Fletcher, N. A. Teanby, J. Hurley, G. S. Orton, G. R. Davis, Icarus 223, 684-698 (2013)

D. Titov, N. Ignatiev, K. McGouldrick, V. Wilquet, C. F. Wilson, Space Sci. Rev. 214, 126 (2018)

D. Toledo, P. G. J. Irwin, P. Rannou, N. A. Tenby, A. A. Simon, M. H. Wong, G. S. Orton, Icarus 333, 1-11 (2019)

R. Vaillon, J.-M. Geffrin, J. Quant. Spectrosc. Radiat. Transf. 146, 100-105 (2014)

van de Hulst, H.C., Light Scattering from Small Particles (John Wiley \& Sons Inc., New York, 1957)

C. Verhaege, V. Shcherbakov, P. Personne, J. Quant. Spectrosc. Radiat. Transf. 110, 1690-1697 (2009) 